\title{
Are There Modifiable Environmental Factors Related to Amyotrophic Lateral Sclerosis?
}

\author{
Bozenna Kuraszkiewicz, Teresa Podsiadły-Marczykowska, Hanna Goszczyńska \\ and Maria Piotrkiewicz*
}

Department of Brain Imaging and Investigation of Nervous System Function, Nalecz Institute of Biocybernetics and Biomedical Engineering, Polish Academy of Sciences, Warsaw, Poland

Keywords: amyotrophic lateral sclerosis, risk factors, trial size, age factor, dietary habits, gut microbiome, psychological stress, oxidative damage

Amyotrophic lateral sclerosis (ALS) is a fatal adult-onset neurodegenerative disorder of unknown etiology and no preventive treatment. It is characterized by degeneration of both upper motoneurons in the primary motor cortex and lower motoneurons in the brainstem and spinal cord. It results in progressive muscular weakness and atrophy, leading eventually to respiratory insufficiency and death. Approximately $50 \%$ of patients with ALS die within 30 months of symptom onset (1). Although ALS is considered a rare disease (incidence between 0.6 and 2.6 new cases per year per 100,000 , prevalence $3-8$ per 100,000 ), it is in fact more common than generally recognized, with an adult lifetime risk of 1 in 400 (2). Approximately 10\% of all ALS cases are familial (fALS), and the remaining $90 \%$ are sporadic (sALS). Genetic factors are involved in the pathogenesis of fALS and up to $15 \%$ of sALS $(3,4)$.

Nowadays, the only established risk factors for ALS are advanced age, male gender, and certain genetic mutations (1). Given that no more than $25 \%$ of all ALS diagnosis has genetic basis, for the remaining percentage of cases gene-environmental interaction may be responsible.

In the recent years, a vast number of studies addressing ALS risks related to the exposure to environmental factors have been published [for a recent review, see Ref. (5)]. Their analysis is difficult, since they applied various methods of data collection and analysis, from studying of toxicants' content in tissue samples, through case-control studies and analysis of death certificates, to reviews and meta-analyses. Original studies were usually performed on small local patient cohorts, and their results are ambiguous and often contradictory. Virtually all so far published reviews on ALS risk factors were inconclusive and called for further investigations.

Nevertheless, as mentioned earlier, at least $75 \%$ of ALS cases do not have established genetic basis, so the search for modifiable environmental factors continues. The research in this field is important, since it may lead to formulation of measures, which could prevent this fatal disease or at least delay its development. Therefore, we decided to put forward some thoughts that arose from studying published literature, hoping that they could help to design future successful studies on ALS risk factors.

\section{THE SIZE OF AN INDIVIDUAL TRIAL}

Systematic reviews and meta-analyses are often viewed as tools which may overcome weaknesses of small trials. However, as stated by Bartolucci and Hillegass (6), “... one should keep in mind that meta-analyses should neither be a replacement for well-designed large-scale randomized studies nor a justification for conducting small underpowered studies." Moreover, it has been pointed out that individual small trials are more prone to biases, which will affect final conclusions of meta-analyses (7). That is actually one of the main drawbacks of so far reported research on ALS risk factors. Even in the most exhaustive review recently published (5), the meta-analyses were based on many studies with small sample size (see Table 1). Evidently, the authors were not able to find sufficient number 
TABLE 1 | Exposure to environmental factors: results of meta-analyses (5).

\begin{tabular}{|c|c|c|c|c|c|c|c|c|c|c|}
\hline \multirow[t]{2}{*}{ Risk factor } & \multirow{2}{*}{$\begin{array}{c}\text { Papers } \\
\text { No. }\end{array}$} & \multirow[t]{2}{*}{ Publication dates } & \multicolumn{3}{|c|}{ Patients } & \multicolumn{3}{|c|}{ Controls } & \multirow[t]{2}{*}{ Significance $P$} & \multirow[t]{2}{*}{ OR $(95 \% \mathrm{Cl})$} \\
\hline & & & No. & Range & $n^{a}$ & No. & Range & $n^{\mathrm{a}}$ & & \\
\hline Heavy metals (lead) & $11(7)$ & $1981-2009$ & 1,459 & $56-518$ & 1 & 1,887 & $66-518$ & 3 & $<0.00001$ & $1.71(1.38,2.11)$ \\
\hline Agricultural chemicals (pesticides) & $12(10)$ & 1993-2013 & 2,144 & $41-661$ & 2 & 99,612 & $64-84,698$ & 6 & 0.0001 & $1.57(1.43-6.3)$ \\
\hline Organic solvents & 7 & 1991-2010 & 701 & $36-174$ & 0 & 1,286 & $92-348$ & 3 & 0.007 & $1.43(1.10-1.86)$ \\
\hline Previous trauma & 17 & 1981-2012 & 2,955 & $25-518$ & 5 & 3,763 & $50-518$ & 6 & $<0.00001$ & $1.73(1.43-2.09)$ \\
\hline Electric shock & 6 & 1983-1999 & 961 & $25-518$ & 1 & 1,154 & $50-518$ & 2 & $<0.0001$ & $3.27(1.87-5.83)$ \\
\hline Professional sports & 4 & 1998-2012 & 824 & $61-377$ & 2 & 1,082 & $112-377$ & 3 & Significant & $1.35(1.11-1.65)$ \\
\hline
\end{tabular}

aNumber of studies with >200 participants.

of papers with acceptable homogeneity and eventually concluded: "... as the number of studies included in most meta-analyses in this study was small, caution should be used when interpreting the findings." Summing up, if future meta-analyses are to produce reliable results, they should be based on the properly designed original studies of sufficiently large size. The description of methods to calculate a sufficient size of the study, which aims toward determination of the effect of a given factor on the ALS risk, can be found in Ref. (8). The author provided an example of such calculation for a study aiming at the detection of an informational odds ratio of at least 2.0 at the $\alpha=0.05$ level of statistical significance when the proportion of non-diseased individuals, who are exposed to a given environmental risk, equals 0.10 . In such a case, to obtain a sufficient power $(>80 \%)$, the study needs 200 diseased and 200 non-diseased participants. As can be seen in Table 1, this number of patients was exceeded only in few studies included in meta-analyses of Wang et al.

As ALS is a rare disease, large studies can be performed only in international cooperation. An effort to create the big ALS database was undertaken in the ongoing project "OnWebDUALS," aiming toward collection and subsequent analysis of standardized questionnaires from several hundreds of patients (http://www. neurodegenerationresearch.eu/wp-content/uploads/2015/02/ ONWebDUALS.pdf). The statistical analysis applying modern methodology will take into account patients' genetic and phenotypic diversity and hopefully will come with novel associations between individual factors and ALS risk. USA National ALS Registry (9) and Australian Web database (10) should also be mentioned. The need for big data was acknowledged by European Commission who recently issued a call SC1-DTH-08-2018: Prototyping a European interoperable Electronic Health Record exchange, aiming to merge together individual patient databases existing in different European countries for increasing their statistical power. It is worth trying to use big data to conduct studies on those risk factors, which have been shown to relate to known mechanisms responsible for ALS development, in particular factors collected in Table $\mathbf{1 .}$

\section{AGE FACTOR}

The incidence of ALS increases with age and peaks in mid seventies, with very few new cases below 25 and above 90 years old $(11,12)$. There is an "age-related cascade of neurodegeneration" (13), whereby accumulative oxidative damage provokes metabolic deficiencies, protein aggregation, decline in mitochondrial function, and inflammation (14-16). There is also evidence of heavy metals accumulation with age in spinal interneurons and in motoneurons (17). Exposure to these and other environmental pathogens will accelerate neurodegeneration cascade, which will be accompanied by telomere shortening, a widely known determinant of cell senescence. Indeed, accelerated telomere shortening was observed in ALS mice (18) and in leukocytes from sporadic ALS patients (19). Telomere shortening in ALS certainly deserves more attention, since it may be modified by a healthy lifestyle (20). Summing up, susceptibility to the environmental risks would increase with age that is in line with abovementioned age dependency of ALS incidence. The future studies might be presumably more conclusive if the analysis was carried on in distinct age groups.

\section{DIETARY HABITS}

The studies on possible influences of diet on ALS are rather scarce. A higher ALS risk was associated with increased dietary uptake of fat and glutamate $(21,22)$. A decreased risk was observed in individuals whose diet was rich in fiber (21) or green-yellow vegetables (23). Higher intake of antioxidants and carotenes from fruit and vegetables was associated with better patient's condition [higher ALSFRS-R scores (24)]. In several studies, a long-term vitamin E supplementation was associated with lower ALS rates $(25,26)$, although in some other studies such a relationship was not observed [e.g., Ref. $(21,27)]$. An interesting observation was made by Felmus et al. $(28,29)$. They found that ALS patients drank more milk than control subjects. To the best of our knowledge, milk was not considered a potential ALS risk factor in any other study. However, diary consumption was shown to be associated with increased risk of Parkinson's disease (30). Summing up, we think that more attention should be paid to the effects of diet, especially in context of its antioxidant capacity. Diary consumption should also be taken into account as the potential risk factor.

\section{GUT MICROBIOME}

The interest in the role of gut microbiome in health and disease is recently growing $(31,32)$. The importance of healthy gut microbiome has been shown in three most recent articles published in Science, reporting that the patients with low levels 
of the bacterium Akkermansia muciniphila poorly responded to antitumor treatment (33-35). Moreover, a few papers have recently highlighted a potential link of gut dysbiosis and neurodegenerative diseases (35-38). Fang et al. (39) found significantly increased population of harmful microorganisms (genus Dorea) and significantly reduced population of beneficial microorganisms (genus Oscillibacter, Anaerostipes, Lachnospiraceae) in ALS patients and suggested that the imbalance in intestinal microflora constitution has a strong association with ALS pathogenesis. Recent studies revealed signs of leaky intestine in G93A ALS mouse model $(40,41)$, which were associated with reduced levels of Butyrivibrio fibrisolvens, Escherichia coli, and Fermicus, as compared with wild-type mice. The leaking intestine might be at least partially responsible for the observed discordance between increased presymptomatic total daily energy intake and decreased presymptomatic body mass index in ALS patients (22). These aspects are worth considering in future studies.

\section{PSYCHOLOGICAL STRESS}

The studies investigating association of ALS with psychological stress are very rare. The study of Okamoto et al. (23), who observed increased ALS risk in patients reporting "type A behavior" and high or moderate level of stress, was the only one directly addressing this issue, which we were able to find. Type A behavior was not defined in this study and the self-reported stress intensity was based on 4-point scale (never/hardly, light, moderate, and high). Nevertheless, psychological stress is significantly associated with higher oxidative stress, lower telomerase activity, and shorter telomere length (42), all involved in ALS. It should also be noted that

\section{REFERENCES}

1. Ingre C, Roos PM, Piehl F, Kamel F, Fang F. Risk factors for amyotrophic lateral sclerosis. Clin Epidemiol (2015) 7:181-93. doi:10.2147/CLEP.S37505

2. Armon C. Sports and trauma in amyotrophic lateral sclerosis revisited. J Neurol Sci (2007) 262:45-53. doi:10.1016/j.jns.2007.06.021

3. Andersen PM, Al-Chalabi A. Clinical genetics of amyotrophic lateral sclerosis: what do we really know? Nat Rev Neurol (2011) 7:603-15. doi:10.1038/ nrneurol.2011.150

4. Alsultan A, Waller R, Heath P, Kirby J. The genetics of amyotrophic lateral sclerosis: current insights. Degener Neurol Neuromusc Dis (2016) 6:49-64. doi:10.2147/DNND.S84956

5. Wang M-D, Little J, Gomes J, Cashman NR, Krewski D. Identification of risk factors associated with onset and progression of amyotrophic lateral sclerosis using systematic review and meta-analysis. Neurotoxicology (2017) 61:101-30. doi:10.1016/j.neuro.2016.06.015

6. Bartolucci AA, Hillegass WB. Overview, strengths, and limitations of systematic reviews and meta-analyses. In: Chiappelli F, editor. Evidence-Based Practice: Toward Optimizing Clinical Outcomes. Berlin, Heidelberg: Springer (2010). p. 17-33.

7. Guyatt GH, Mills EJ, Elbourne D. In the era of systematic reviews, does the size of an individual trial still matter? PLoS Med (2008) 5:e4. doi:10.1371/journal. pmed.0050004

8. Efird JT. Computing power and sample size for informational odds ratio. Int J Environ Res Public Health (2013) 10:5239-43. doi:10.3390/ijerph10105239

9. Malek AM, Stickler DE, Antao VC, Horton DK. The National ALS Registry: a recruitment tool for research. Muscle Nerve (2014) 50:830-4. doi:10.1002/ mus. 24421

10. Parkin Kullmann JA, Hayes S, Wang MX, Pamphlett R. Designing an internationally accessible web-based questionnaire to discover risk factors for the most severe telomere shortening was found to be associated with stress occurring in childhood (43). Therefore, we think that the retrospective questionnaires should address the stressful events, with special attention paid to those happening in childhood.

\section{CONCLUDING REMARKS}

Summing up, we think that future studies on ALS risk factors should be carefully designed and should involve sufficiently large patient cohorts. The international studies should consider potential risks with established relation to the commonly accepted ALS mechanisms, but also those less investigated but potentially important as gut health, dietary habits, and psychological stress. The evaluation of the last two factors should involve a consensus on the ways to measure their impact.

\section{AUTHOR CONTRIBUTIONS}

BK, TP-M, and HG: Participation in literature collection, discussion, and contribution to final manuscript. MP: Participation in literature collection, manuscript drafting, discussion, and contribution to final manuscript.

\section{ACKNOWLEDGMENTS}

This opinion was supported by the grant No. JPND/01/2015 funded by Polish National Center of Research and Development in frames of EU Joint Program of Neurodegenerative Research. Many thanks are due to Prof. Magdalena Kuźma-Kozakiewicz for her valuable comments. amyotrophic lateral sclerosis: a case-control study. JMIR Res Protoc (2015) 4:e96. doi:10.2196/resprot.4840

11. Alonso A, Logroscino G, Jick SS, Hernán MA. Incidence and lifetime risk of motor neuron disease in the United Kingdom: a population-based study. Eur J Neurol (2009) 16:745-51. doi:10.1111/j.1468-1331.2009.02586.x

12. Bäumer D, Talbot K, Turner MR. Advances in motor neurone disease. J R Soc Med (2014) 107:14-21. doi:10.1177/0141076813511451

13. Drechsel DA, Estevez AG, Barbeito L, Beckman JS. Nitric oxide-mediated oxidative damage and the progressive demise of motor neurons in ALS. Neurotox Res (2012) 22:251-64. doi:10.1007/s12640-012-9322-y

14. Kirkwood TB, Kowald A. Network theory of aging. Exp Gerontol (1997) 32:395-9. doi:10.1016/S0531-5565(96)00171-4

15. Cui H, Kong Y, Zhang H. Oxidative stress, mitochondrial dysfunction, and aging. J Signal Transd (2012) 2012:646354. doi:10.1155/2012/646354

16. García ML, Fernández A, Solas MT. Mitochondria, motor neurons and aging. J Neurol Sci (2013) 330:18-26. doi:10.1016/j.jns.2013.03.019

17. Pamphlett R, Kum Jew S. Age-related uptake of heavy metals in human spinal interneurons. PLoS One (2016) 11:e0162260. doi:10.1371/journal.pone. 0162260

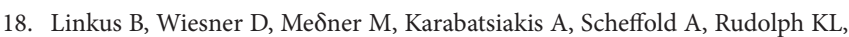
et al. Telomere shortening leads to earlier age of onset in ALS mice. Aging (Albany NY) (2016) 8:382-91. doi:10.18632/aging.100904

19. De Felice B, Annunziata A, Fiorentino G, Manfellotto F, D’Alessandro R, Marino R, et al. Telomerase expression in amyotrophic lateral sclerosis (ALS) patients. J Hum Genet (2014) 59:555-61. doi:10.1038/jhg.2014.72

20. Cassidy A, De Vivo I, Liu Y, Han J, Prescott J, Hunter DJ, et al. Associations between diet, lifestyle factors, and telomere length in women. Am J Clin Nutr (2010) 91:1273-80. doi:10.3945/ajcn.2009.28947

21. Nelson LM, Matkin C, Longstreth WT Jr, Mcguire V. Population-based case-control study of amyotrophic lateral sclerosis in western Washington 
State. II. Diet. Am J Epidemiol (2000) 151:164-73. doi:10.1093/oxfordjournals. aje.a010184

22. Huisman MB, Seelen M, Van Doormaal PC. Effect of presymptomatic body mass index and consumption of fat and alcohol on amyotrophic lateral sclerosis. JAMA Neurol (2015) 72:1155-62. doi:10.1001/jamaneurol.2015.1584

23. Okamoto K, Kihira T, Kondo T, Kobashi G, Washio M, Sasaki S, et al. Lifestyle factors and risk of amyotrophic lateral sclerosis: a case-control study in Japan. Ann Epidemiol (2009) 19:359-64. doi:10.1016/j.annepidem.2009.01.015

24. Nieves JW, Gennings C, Factor-Litvak P. Association between dietary intake and function in amyotrophic lateral sclerosis. JAMA Neurol (2016) 73:1425-32. doi:10.1001/jamaneurol.2016.3401

25. Wang H, O’reilly ÉJ, Weisskopf MG, Logroscino G, Mccullough ML, Schatzkin A, et al. Vitamin E intake and risk of amyotrophic lateral sclerosis: a pooled analysis of data from 5 prospective cohort studies. Am JEpidemiol (2011) 173:595-602. doi:10.1093/aje/kwq416

26. Freedman DM, Kuncl RW, Weinstein SJ, Malila N, Virtamo J, Albanes D. Vitamin E serum levels and controlled supplementation and risk of amyotrophic lateral sclerosis. Amyotroph Lateral Scler Frontotemporal Degener (2013) 14:246-51. doi:10.3109/21678421.2012.745570

27. Galbussera A, Tremolizzo L, Brighina L, Testa D, Lovati R, Ferrarese C, et al. Vitamin $\mathrm{E}$ intake and quality of life in amyotrophic lateral sclerosis patients: a follow-up case series study. Neurol Sci (2006) 27:190-3. doi:10.1007/ s10072-006-0668-x

28. Felmus MT, Patten BM, Swanke L. Antecedent events in amyotrophic lateral sclerosis. Neurology (1976) 26:167-72. doi:10.1212/WNL.26.2.167

29. Pierce-Ruhland R, Patten BM. Repeat study of antecedent events in motor neuron disease. Ann Clin Res (1981) 13:102-7.

30. Hughes KC, Gao X, Kim IY, Wang M, Weisskopf MG, Schwarzschild MA, et al. Intake of dairy foods and risk of Parkinson disease. Neurology (2017) 89:46-52. doi:10.1212/wnl.0000000000004057

31. Shen TD. Diet and gut microbiota in health and disease. Nestle Nutr Inst Workshop Ser (2017) 88:117-26. doi:10.1159/000455220

32. Wang $\mathrm{Y}$, Wang $\mathrm{B}$, Wu J, Jiang $\mathrm{X}$, Tang $\mathrm{H}$, Nielsen $\mathrm{OH}$. Modulation of gut microbiota in pathological states. Engineering (2017) 3:83-9. doi:10.1016/J. ENG.2017.01.013

33. Gopalakrishnan V, Spencer CN, Nezi L, Reuben A, Andrews MC, Karpinets TV, et al. Gut microbiome modulates response to anti-PD-1 immunotherapy in melanoma patients. Science (2018) 359:97-103. doi:10.1126/science.aan4236

34. Matson V, Fessler J, Bao R, Chongsuwat T, Zha Y, Alegre M-L, et al. The commensal microbiome is associated with anti-PD-1 efficacy in metastatic melanoma patients. Science (2018) 359:104-8. doi:10.1126/science.aao3290
35. Routy B, Le Chatelier E, Derosa L, Duong CPM, Alou MT, Daillère R, et al. Gut microbiome influences efficacy of PD-1-based immunotherapy against epithelial tumors. Science (2018) 359:91-7. doi:10.1126/science. aan3706

36. Fang X. Potential role of gut microbiota and tissue barriers in Parkinson's disease and amyotrophic lateral sclerosis. Int J Neurosci (2016) 126:771-6. doi:10.3109/00207454.2015.1096271

37. Scheperjans F. Can microbiota research change our understanding of neurodegenerative diseases? Neurodegener Dis Manag (2016) 6:81-5. doi:10.2217/ nmt-2015-0012

38. Rowin J, Xia Y, Jung B, Sun J. Gut inflammation and dysbiosis in human motor neuron disease. Physiol Rep (2017) 5:e13443. doi:10.14814/phy2.13443

39. Fang X, Wang X, Yang S, Meng F, Wang X, Wei H, et al. Evaluation of the microbial diversity in amyotrophic lateral sclerosis using high-throughput sequencing. Front Microbiol (2016) 7:1479. doi:10.3389/fmicb.2016.01479

40. Wu S, Yi J, Zhang YG, Zhou J, Sun J. Leaky intestine and impaired microbiome in an amyotrophic lateral sclerosis mouse model. Physiol Rep (2015) 3:e12356. doi:10.14814/phy2.12356

41. Zhang YG, Wu S, Yi J, Xia Y, Jin D, Zhou J, et al. Target intestinal microbiota to alleviate disease progression in amyotrophic lateral sclerosis. Clin Ther (2017) 39:322-36. doi:10.1016/j.clinthera.2016.12.014

42. Mathur MB, Epel E, Kind S, Desai M, Parks CG, Sandler DP, et al. Perceived stress and telomere length: a systematic review, meta-analysis, and methodologic considerations for advancing the field. Brain Behav Immun (2016) 54:158-69. doi:10.1016/j.bbi.2016.02.002

43. Puterman E, Gemmill A, Karasek D, Weir D, Adler NE, Prather AA, et al. Lifespan adversity and later adulthood telomere length in the nationally representative US Health and Retirement Study. Proc Natl Acad Sci U S A (2016) 113:E6335-42. doi:10.1073/pnas.1525602113

Conflict of Interest Statement: The authors declare that the research was conducted in the absence of any commercial or financial relationships that could be construed as a potential conflict of interest.

Copyright (C) 2018 Kuraszkiewicz, Podsiadly-Marczykowska, Goszczyńska and Piotrkiewicz. This is an open-access article distributed under the terms of the Creative Commons Attribution License (CC BY). The use, distribution or reproduction in other forums is permitted, provided the original author(s) and the copyright owner are credited and that the original publication in this journal is cited, in accordance with accepted academic practice. No use, distribution or reproduction is permitted which does not comply with these terms. 